\title{
$K R A S$ Mutation in an Implant-associated Peripheral Giant Cell Granuloma of the Jaw: Implications of Genetic Analysis of the Lesion for Treatment Concept and Surveillance
}

\author{
REINHARD E. FRIEDRICH ${ }^{1 *}$, FALK WÜSTHOFF $^{1 *}$, ANDREAS M. LUEBKE ${ }^{2}$, \\ FELIX K. KOHLRUSCH ${ }^{1}$, ILSE WIELAND ${ }^{3}$, MARTIN ZENKER ${ }^{3}$ and MARTIN GOSAU ${ }^{1}$ \\ ${ }^{1}$ Department of Oral and Maxillofacial Surgery, Eppendorf University Hospital, \\ University of Hamburg, Hamburg, Germany; \\ ${ }^{2}$ Institute of Pathology, Eppendorf University Hospital, University of Hamburg, Hamburg, Germany; \\ ${ }^{3}$ Institute of Human Genetics, Otto-von-Guericke University Magdeburg, Magdeburg, Germany
}

\begin{abstract}
The aim of this case report was to detail diagnosis and therapy in a case of implant-associated peripheral giant cell granuloma (IA-PGCG) of the jaw. Case Report: The 41-year-old female attended the outpatient clinic for treatment of recurrent mandibular IA-PGCG. The lesion was excised and the defect was closed with a connective tissue graft of the palate. Healing of oral defects was uneventful, and no local recurrence has occurred during a follow-up of 7 months. Genetic examination of the lesion identified a somatic mutation in KRAS. Conclusion: The lesions are assessed as reactive-inflammatory changes in the mucous membrane of the oral cavity. The cause of the lesion is unknown. KRAS mutations are commonly found in various cancer tissues, but also in germline and mosaic RASopathies. Recently, KRAS mutations have been identified in several IA$P G C G$. The clinical course of a frequently locally recurring lesion gives rise to the assumption that lesions of this type show characteristics known in benign neoplasms.
\end{abstract}

Restoring edentulous jaw regions with bone-anchored implants has become a standardized technique for fixing dentures. The osseous-integrated implant causes a permanent exposure of bone and soft tissue to inflammatory agents. The

This article is freely accessible online.

*These Authors contributed equally to the study.

Correspondence to: Reinhard E. Friedrich, MD, DMD, Ph.D., FEBOMFS, Department of Oral and Maxillofacial Surgery, Eppendorf University Hospital, Martinistr. 52, 20246 Hamburg, Germany, Tel.: +49 40741053259, E-Mail: rfriedrich@uke.de

Key Words: Giant cell granuloma, epulis gigantocellularis, dental implant, KRAS mutation. constant irritation of the local tissue by the therapeutic measures is kept to a minimum by careful treatment planning and permanent oral care. However, severe inflammatory reactions can arise in the peri-implant area, often in connection with activation of osteoclasts and peri-pillar bone loss. In individual cases a rapidly growing tumor-like mucous tissue hyperplasia develops in the immediate vicinity of the implant (1). In some cases and case series reported on this phenomenon so far, the peri-implant inflammatory reaction was a peripheral giant cell granuloma of the jaw (PGCG) (122). PGCG are well known inflammatory alterations in the oral mucosa (23-26). The pathogenesis of the lesion is yet unknown. The relationship between oral implants and PGCG has become a focus of broader scientific interest in the last few years (9-22). It has recently been shown that some of the implant-associated PGCG (IA-PGCG) have mutations in a gene that is important for the development of neoplasms, the rat sarcoma (RAS) proto-oncogene (27). Kirsten rat sarcoma virus $(K R A S)$ gene belongs to the family of RAS genes that play an essential role in the development and progression of various neoplasms $(28,29)$. The detection of KRAS mutations in a lesion of the oral mucous membrane currently assessed as of inflammatory origin prompted us to examine a case with IA-PGCG in more detail and to adapt surgical therapy to recent knowledge about the lesion's pathogenesis.

\section{Case Report}

The 41-year-old female patient of Indian origin had been referred for further treatment by a resident oral maxillofacial surgeon. One year before, the patient had developed a soft tissue tumor in the right molar region that was excised by the referring surgeon. The histological diagnosis of the lesion was epulis gigantocelluraris. However, the tumor had grown again within six months after surgery and was excised again. 
The initial diagnosis of the lesion was confirmed. After a second recurrence, the lesion had reached considerable size another 7 months later, the patient was referred to the Oral and Maxillofacial Surgery Clinic, Eppendorf University Hospital, for further treatment. The patient had no previous general or oral illnesses. In particular, the patient has not experienced any similar oral lesions so far and the oral health situation was normal in the period up to the development of the mucosal proliferation.

The dental implant was placed in the lower jaw abroad 3 years ago. The patient could not provide any information about the implant manufacturer. Surgical care at that time was without local complications.

Orally, a partly fibrous, partly livid discolored, raised oral mucosa has grown circularly around the crown of the lower right second premolar. Except for the lesion, the oral mucosa was normal. A crown was fixed on the dental implant. The implant was firmly fixed in the bone. The radiological examination showed slight horizontal, but no vertical bone loss in the peri-implant area. The visible findings corresponded to the imprecise criteria applicable in the case of 'epulis'. Due to two recurrent lesions at this site, it was planned to perform a wide excision, removing a thin layer of bone from the base of the lesion, and defect coverage with non-gingival oral tissue distant to the site of lesion. In local anesthesia, the peri-implant soft tissue lesion was cut around with safety margin of unaffected mucosa and then completely removed from the alveolar process. The bone was carefully smoothed to remove any residual portions of the tumor-like lesion. Then a palatal connective tissue graft of the left side was harvested, positioned around the implant, and fixed with sutures. Finally, the vestibular and lingual oral mucosa was mobilized, and tight epithelial coverage of the peri-implant defect was achieved (Figure 1). Wound healing was uneventful at both sites of oral surgery. Seven months following treatment of the second relapse of the lesion, the graft has healed without signs indicating any peri-implant infection.

Histology. The round, solid soft tissue lesion was covered by intact epithelium. Macroscopically, there was a distinct, capsule-like layer separating the lesion from the surrounding mucosa. However, no capsule-like border could be identified at the base of the lesion. Microscopically, the lesion showed the characteristic accumulation of giant cells mixed with numerous small-cell tumor cells showing a prominent nucleus. Occasionally there were residues of previous hemorrhages scattered within the lesion. Representative histological photomicrographs are reproduced in Figure 2.

Genetics. The aim of the investigation was to detect a mutation in a gene relevant for suspected postzygotic mosaic RASopathy. After the patient's DNA had been purified, the polymerase chain reaction (PCR) fragments were analyzed by standard Sanger sequencing and an automatic sequencer (ABI3500XL, ThermoFisher, Waltham, MA, USA). The sequences determined in this way were compared to the reference sequence. The genes KRAS (NM_004985), exons 2,3, HRAS (NM_005343), exons 2,3, and NRAS (NM_002524), exons 2-3, were examined. A pathogenic sequence change was detected KRAS: c.=/35G $>$ A $\mathrm{p} .=/ \mathrm{Gly} 12 \mathrm{Asp}$ [p.G12D]. The proportion of the mutant allele in the tumor is approximately $21 \%$, and in the mucosa covering the lesion approximately $14 \%$. No mutation could be detected in the tissue surrounding the excised lesion, i.e., in the marginal normal mucosa. The genetic results confirm a KRAS mosaic in the peri-implant PGCG.

\section{Discussion}

This case report describes advanced diagnostics of a periimplant hyperplastic mucosal lesion and the implant-preserving therapy adapted to the patient's medical history. The histological findings confirmed the suspicion of PGCG. The jaw below the lesion was intact. Clinical and morphological findings of the lesion indicate the case of a PGCG adjacent to a dental implant. The special feature about the well-known oral lesion in this case and in similar cases is the temporospatial connection with the insertion of a dental implant.

Peripheral and central giant cell granuloma. PGCG and central giant cell granuloma (CGCG) are differentiated according to their topography, but do not differ morphologically from one another (23, 30). Different pathogenesis of both lesions was discussed for a long time. The central lesion probably is of non-odontogenic origin. CGCG is only rarely noted in specimen obtained of periapical region (31). The local findings rule out a CGCG in the present case.

PGCG of the jaw is classified as a non-neoplastic lesion of unknown etiology (26). There have been repeated notions communicated suspecting local inflammation of the teeth and the oral mucosa may have preceded the development of the peculiar mucosal hyperplasia (23). Retrospective study results prove the topographical connection between dental findings and the development of the lesions in many cases (25). However, the odontogenic pathogenesis of the lesion has not been proven beyond doubt (24). Indeed, observations based on case studies were also published that had not identified a causal tooth or tooth remnants in the area of the lesion. PGCG may develop even in case of toothlessness $(24,25)$. An unusual aspect of the entity is the well-known high rate of recurrence, as in the present case where two recurrence had been treated within one year. Review articles on PGCG suggest that a local recurrence is to be expected in about one in 10 patients (26). On the other hand, the recurrence rate for IA-PGCG is higher, calculated to be about one in three cases (21). 

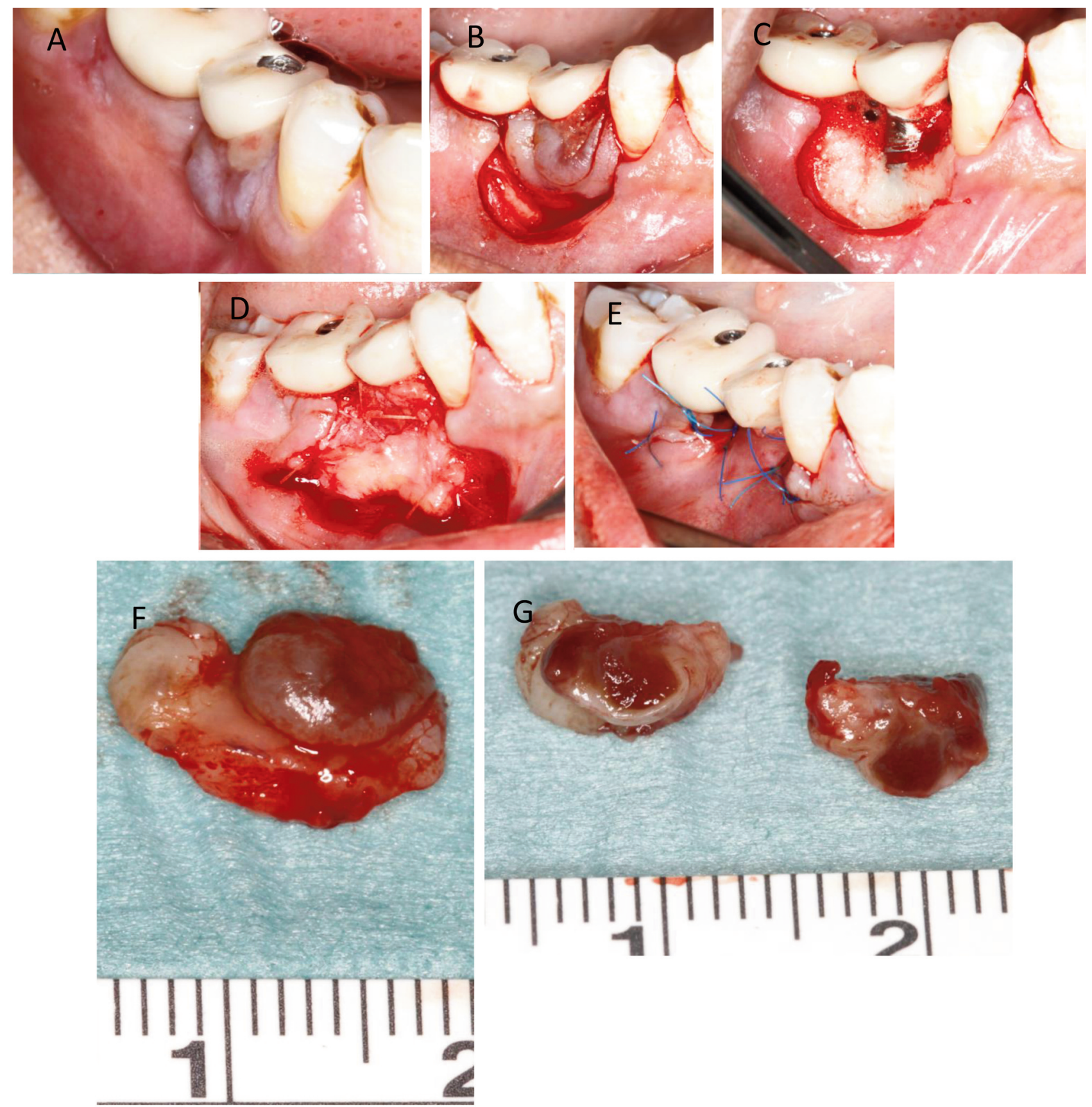

Figure 1. Excision and covering of the mucogingival defect with connective tissue flaps. (A) Vestibular view of the peri-implant lesion on the right side of the lower jaw. (B) Circular excision of the soft tissue around the lesion (with safety margin of apparently normal mucosa). (C) Peri-implant soft tissue defect. (D) Palatal connective tissue transplant situated on the vestibular defect side. (E) Epithelial coverage of the graft by mobilized marginal mucosa. $(F)$ Excised specimen in toto and $(G)$ after cutting the lesion in two halves exposing the erythematous lesion.

IA-PGCG. IA-PGCG were already described some time ago as a special form of giant cell lesion $(1,2)$, but only in the last few years have there been reported additional diagnostic and therapeutic experiences, predominantly collected in individual cases (3-22). Some authors provide data derived from collective statistics from case reports $(20,21)$. However, at present IA-PGCG is more of a recently described complex of findings than a well-defined entity. However, some genetic studies provide significant advances in understanding pathogenesis (27). 


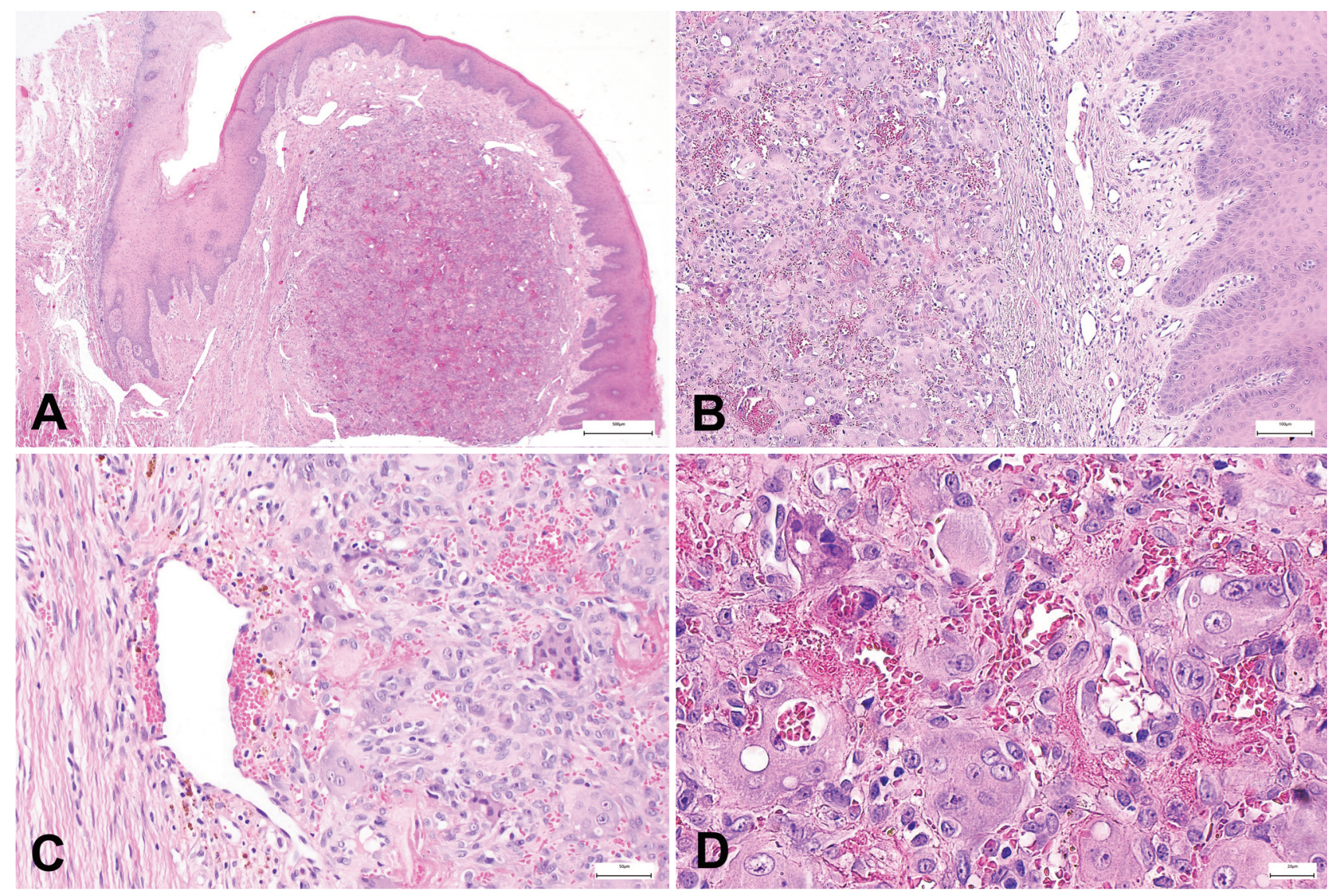

Figure 2. (A) Histology revealed a nodular lesion located beneath the squamous epithelium, limited to the gingiva. (B) This nodule had no capsule but was relatively well-circumscribed. (C) The lesion consisted of mononuclear spindle-shaped and polygonal cells, as well as prominent multinucleated giant cells. The background was well vascularized with fresh hemorrhage and hemosiderin pigment. (D) The nuclei of the mononuclear component and the giant cells were identical. Cellular atypia was not detectable. In summary, the lesion was classified as a characteristic example of peripheral giant cell granuloma.

KRAS mutation and IA-PGCG. In a recently published study, KRAS mutations were found in $8 / 15$ cases $(53.4 \%$ ) of IA-PGCG (27), including changes at codon 12: One 70-year-old female patient had a p.G12A mutation. In this case, peri-implant bone resorption had been demonstrated. Another female patient of the same age had the KRAS mutation p.G12D, without any bone lesions (27). This mutation p.G12D is found in the presented patient. The number of known cases with these mutations is still too few to describe a geno-phenotype correlation, concerning osteolysis of adjacent bone. It is also unclear when the lesion begins to develop, and which factors determine the direction of the lesion's spread into adjacent tissues and further biological properties. The time interval between the insertion of the dental implant and the development of a PGCG varies between a few weeks and many years (19).

Interesting is the evidence that KRAS mutations have been detected in CGCG (32) and in patients with oculocutaneous mosaic RASopathies (33). Besides cases of IA-PGCG, mutations at codon 12 of KRAS gene have already been described in lesions of different morphology and arising in various types of mosaic RASopathies, e.g., in nevus sebaceous and Schimmelpenning syndrome $(29,33)$, and in keratinocyte epidermal nevus syndrome $(34,35)$.

KRAS mutation and RASopathy. The somatic KRAS mutation c. $35 \mathrm{G}>\mathrm{A}$ is the most common $K R A S$ mutation in human cancer (29). As a germline mutation, the mutation is probably lethal because it only has been detected as a somatic mutation so far. The hypothesis of oncogenic mutations surviving only in a somatic mosaic status was formulated by Happle to characterize genetically determined mosaic diseases that only occur sporadically (36). Accordingly, somatic KRAS mutations at the typical sites mutated in cancer, which are known to cause strong pathway activation, can be detected in various mosaic RASopathies. It is assumed that mutations observed in mosaic 
RASopathies and cancer aggregate in hotspots that differ from those in germline RASopathies $(29,37)$. However, the differences in mutation patterns have not provided a clear indication of a geno-phenotype correlation so far.

The detection of KRAS mutations in CGCG is considered to provide evidence of the neoplastic biology of the lesion (32). CGCG is rated as the gnathic correlate to the nonossifying fibroma (NOF) of long bones (38). However, NOF of long bones is a lesion with limited growth capacity and a high rate of spontaneous regression. Although CGCG is usually a lesion limited in growth, there is hardly any tendency towards regression (23). It remains to be determined whether the similarities and differences between CGCG and NOF are also reflected by a common or distinct molecular pathogenesis. For this reason, it has not yet been clarified whether a common KRAS activated mitogenic pathway in fibrous lesions includes PGCG, especially implant-associated lesions. At least the pattern of KRAS mutations in IA-PGCG was rated as like conventional PGCG (27). However, it must be kept in mind that at least $50 \%$ of the IA-PGCG had no KRAS mutation (27) and in a recently published report the lesion developed a few days after insertion of the implant (19). These findings show first, a significant proportion of non-KRAS mutation associated lesions (27) and second, the very likely inflammatory nature of the lesion (19). However, it can be speculated the rapid development of the lesion after implantation may have been promoted by a pre-existing local mutation $(39,40)$.

The more recent terminology on giant cell granuloma uses the umbrella term "lesion" to characterize the alteration, apparently because the biological assessment of the alteration currently cannot be conclusively determined (32). Although $K R A S$ gene mutations are an essential molecular genetic finding in cancer, such mutations have also been detected in chronic inflammations such as pancreatitis or ulcerative colitis (for review: 27). On the other hand, studies on other organs show that mutations of the RAS genes also occur in organs that histologically show no signs of neoplasia (39, 40). However, in the absence of evidence of an inflammatory stimulus and after careful curettage of the affected area leaving a bone defect free of visible soft tissue residues, there are arguments favoring the theory that local recurrences may rather be a sign of a neoplastic process arising from remnant tumor cells than from inflammation.

Implant material and oral inflammation. Most dental implants are made from pure titanium. However, there are always small proportions of other elements or compounds in the workpieces. Both titanium and additions of other substances to the implant are potentially harming, causing allergies following insertion of the foreign body (41). However, toxic effect of titanium-based oral implants is a rare phenomenon (42). The so-called titanium allergy is based, among other arguments, on the recognition that the different components of the implant can trigger an allergic stimulus. To the best of our knowledge, a coincidence of titanium-based implants, a type IV allergy, and PGCG is not yet known. In this case, the provenance of the implant could not be determined. The patient's medical history does not provide any indications of allergy.

Treatment. Restricting treatment to excision of the soft tissue tumor is associated with a high rate of recurrence (23). Additional measures, i.e., curettage or marginal ostectomy, increase the rate of successfully treated lesions to around $85 \%$ (26). These manual measures offer a tried and tested, locally focused therapeutic concept. However, despite these measures, the recurrence rate is still high at well over $10 \%$. In the case of IA-PGCG, removal of the implants was necessary relatively often because of bone loss, recurrence of the lesions and clear signs of peri-implant inflammation (21). To prevent further recurrence of PGCG, a free connective tissue graft was used to cover the defect.

The treatment of giant cell granulomas/lesions of the oral cavity can be very complex and is characterized by recurrent lesions. Morphological studies have shown that many enzymes are activated in the lesions. The spectrum of these proteins has been demonstrated in both central and peripheral GCG (43). The topography of the giant cells in relation to the bone may be another factor that is crucial for osteolysis (43). The defect coverage chosen in this case by a mucosal transplant of an unaffected oral region was intended to allow healthy connective tissue to grow at the site of the tumorous lesion and thus to prevent potential microscopic residues of the granuloma from growing back into the peri-pilar region. However, it remains doubtful whether all remains of the IA-PGCG can be removed from the vertical small defects of the bone in direct contact with the implant with non-bone-removing excisions. So far, this measure has proven to be successful in maintaining the integrity of the peri-implant mucosa.

Monitoring. PGCG is a locally invasive lesion. The lower recurrence rate after local, superficial removal of the adjacent bone confirms the assumption of local invasive growth. Long-term monitoring of the lesion is desirable.

\section{Conclusion}

IA-PGCG is an oral lesion causing oral symptoms and endangers the osseous integrity of the implant. Surgical measures lead the way in treating the lesion. Mutated KRAS genes play an essential role in neoplasia. Recent genetic examinations revealed KRAS mutations in some IA-PGCG. These mutations play very likely a major role in the cell growth of the lesion. The genetic findings of the IA-PGCG are very similar to those of a tumor and it must be considered that 
at least some lesions are local neoplasms. With these genetic results, it becomes apparent that pharmacological treatment strategies for the therapy of IA-PGCG might be developed to supplement surgical measures or become an alternative to ablative surgery.

\section{Conflicts of Interest}

The Authors state that there are no conflicts of interest regarding the publication of the study.

\section{Authors' Contributions}

Concept of the study, treatment of the patient, writing of the manuscript: REF, FW, MG; analysis of the data and review of the literature on the subject: REF, FW, MG, FKK, AML, IL, MZ; histological examination of the tissue samples: ALM; genetic analyzes: IL, MZ; final proof of manuscript for release: all Authors.

\section{Acknowledgements}

This research did not receive any specific grant from funding agencies in the public, commercial, or not-for-profit sectors.

\section{References}

1 Hanselaer L, Cosyn J, Browaeys H and De Bruyn H: [Giant cell peripheral granuloma surrounding a dental implant: case report]. Rev Belge Med Dent 65: 152-158, 1984. PMID: 21384627.

2 Hirshberg A, Kozlovsky A, Schwartz-Arad D, Mardinger O and Kaplan I: Peripheral giant cell granuloma associated with dental implants. J Periodontol 74: 1381-1384, 2003. PMID: 14584874. DOI: $10.1902 /$ jop.2003.74.9.1381

3 Bischof M, Nedir R and Lombardi T: Peripheral giant cell granuloma associated with a dental implant. Int $\mathrm{J}$ Oral Maxillofac Implants 19: 295-299, 2004. PMID: 15101604.

4 Cloutier M, Charles M, Carmichael RP and Sándor GK: An analysis of peripheral giant cell granuloma associated with dental implant treatment. Oral Surg Oral Med Oral Pathol Oral Radiol Endod 103: 618-622, 2007. PMID: 17141536. DOI: 10.1016/j.tripleo.2006.08.003

5 Scarano A, Iezzi G, Artese L, Cimorelli E and Piattelli A: Peripheral giant cell granuloma associated with a dental implant. A case report. Minerva Stomatol 57: 529-534, 2008. PMID: 19078895.

6 Ozden FO, Ozden B, Kurt M, Gündüz K and Günhan O: Peripheral giant cell granuloma associated with dental implants: a rare case report. Int J Oral Maxillofac Implants 24: 1153-1156, 2009. PMID: 20162123.

7 Hernandez G, Lopez-Pintor RM, Torres J and de Vicente JC: Clinical outcomes of peri-implant peripheral giant cell granuloma: a report of three cases. J Periodontol 80: 1184-1191, 2009. PMID: 19563300. DOI: 10.1902/jop.2009.090081

8 Olmedo DG, Paparella ML, Brandizzi D and Cabrini RL: Reactive lesions of peri-implant mucosa associated with titanium dental implants: a report of 2 cases. Int J Oral Maxillofac Surg 39: 503507, 2010. PMID: 20005076. DOI: 10.1016/j.ijom.2009.11.007

9 Peñarrocha-Diago MA, Cervera-Ballester J, Maestre-Ferrín L and Peñarrocha-Oltra D: Peripheral giant cell granuloma associated with dental implants: clinical case and literature review. J Oral Implantol 38 (Spec No): 527-532, 2012. PMID: 22712772. DOI: 10.1563/AAID-JOI-D-11-00143

10 Brown AL, Camargo de Moraes P, Sperandio M, Borges Soares A, Araújo VC and Passador-Santos F: Peripheral giant cell granuloma associated with a dental implant: a case report and review of the literature. Case Rep Dent 2015: 697673, 2015. PMID: 25861485. DOI: 10.1155/2015/697673

11 Pacifici A, Carbone D, Marini R, Sfasciotti GL and Pacifici L: Clinical management of a peri-implant giant cell granuloma. Case Rep Dent 2015: 976756, 2015. PMID: 26788379. DOI: $10.1155 / 2015 / 976756$

12 Galindo-Moreno P, Hernández-Cortés P, Ríos R, SánchezFernández E, Cámara M and O'Valle F: Immunophenotype of dental implant-associated peripheral giant cell reparative granuloma in a representative case report. J Oral Implantol 42: 5560, 2016. PMID: 24059329. DOI: 10.1563/AAID-JOI-D-13-00155

13 Halperin-Sternfeld M, Sabo E and Akrish S: The pathogenesis of implant-related reactive lesions: A clinical, histologic and polarized light microscopy study. J Periodontol 87: 502-510, 2016. PMID: 26832832. DOI: 10.1902/jop.2016.150482

14 Scarano A, Lorusso C, Mortellaro C, Limongelli L, Tempesta A and Favia G: Peripheral giant cell granuloma associated with dental implants. J Craniofac Surg 29: e196-e199, 2018. PMID: 29303864. DOI: $10.1097 /$ SCS .0000000000004281

15 Bornstein MM, Claude A, Meier T and Tinguely M: [Peripheral giant-cell granuloma in peri-implant tissues]. Swiss Dent J 128: 980-981, 2018. PMID: 30525321.

16 Atarbashi-Moghadam F, Atarbashi-Moghadam S, Namdari M and Shahrabi-Farahani S: Reactive oral lesions associated with dental implants. A systematic review. J Investig Clin Dent 9: e12342, 2018. PMID: 29752778. DOI: 10.1111/jicd.12342

17 Baesso RCP, de Lima Jacy Monteiro Barki MC, de Souza Azevedo R, da Costa Fontes KBF, Pereira DL, Tucci R, Pires FR and Picciani BLS: Peripheral giant cell granuloma associated with a dental implant. BMC Oral Health 19: 283, 2019. PMID: 31842866. DOI: 10.1186/s12903-019-0983-2

18 Mordini L: Esthetic management of peripheral giant cell granuloma affecting a dental implant in the esthetic zone. Clin Adv Periodontics 9: 77-82, 2019. PMID: 31498570. DOI: 10.1002/cap.10056

19 Bidra AS, Persenaire MJ and Natarajan E: Management of peripheral giant cell granuloma around complete-arch fixed implantsupported prosthesis: A case series. J Prosthet Dent 122: 181-188, 2019. PMID: 31027952. DOI: 10.1016/j.prosdent.2019.02.014

20 Morais TM, Soares CD, Aguirre Urizar JM, Alberdi-Navarro J, Almeida OP and Pires FR: Peri-implant peripheral giant cell lesions: report of 13 new cases and comparative histological and immunohistochemical analysis with peripheral and central giant cell lesions. Med Oral Patol Oral Cir Bucal 24: e739-e745, 2019. PMID: 31655833 . DOI: $10.4317 /$ medoral.23088

21 Chrcanovic BR, Gomes CC and Gomez RS: Peripheral giant cell granuloma associated with dental implants: a systematic review. J Stomatol Oral Maxillofac Surg 120: 456-461, 2019. PMID: 30677564. DOI: 10.1016/j.jormas.2019.01.010

22 Sotorra-Figuerola D, Lafuente-Ibáñez de Mendoza I, Parra-Pérez $\mathrm{C}$ and Aguirre-Urizar JM: Histopathological analysis of biopsies of "peri-implant inflammatory lesions." Everything is not what it seems. Clin Implant Dent Relat Res 22: 366-372, 2020. PMID: 32378812. DOI: $10.1111 /$ cid.12905 
23 Shafer WG, Hine MK and Levy BM: A textbook of oral pathology. Saunders, Philadelphia, pp. 132-134, 1974.

24 Mighell AJ, Robinson PA and Hume WJ: Peripheral giant cell granuloma: A clinical study of 77 cases from 62 patients, and literature review. Oral Dis 1: 12-19, 1995. PMID: 7553374. DOI: 10.1111/j.1601-0825.1995.tb00151.x

25 Boffano P, Benech R, Roccia F, Gallesio C, Garzaro M and Pecorari G: Review of peripheral giant cell granulomas. J Craniofac Surg 24: 2206-2208, 2013. PMID: 24220447. DOI: $10.1097 /$ SCS.0b013e31829a8316

26 Chrcanovic BR, Gomes CC and Gomez RS: Peripheral giant cell granuloma: An updated analysis of 2824 cases reported in the literature. J Oral Pathol Med 47: 454-459, 2018. PMID: 29569293. DOI: $10.1111 /$ jop.12706

27 Martins-Chaves RR, Guimarães LM, Pereira TDSF, Pereira NB, Chrcanovic BR, Fonseca FP, Lafuente-Ibáñez de Mendoza I, Aguirre-Urizar JM, Gomes CC and Gomez RS: KRAS mutations in implant-associated peripheral giant cell granuloma. Oral Dis 26: 334-340, 2020. PMID: 31758745. DOI: 10.1111/odi.13241

28 Weiss RA: A perspective on the early days of RAS research. Cancer Metastasis Rev 39: 1023-1028, 2020. PMID: 32728828. DOI: $10.1007 / \mathrm{s} 10555-020-09919-1$

29 Groesser L, Herschberger E, Ruetten A, Ruivenkamp C, Lopriore E, Zutt M, Langmann T, Singer S, Klingseisen L, Schneider-Brachert W, Toll A, Real FX, Landthaler M and Hafner C: Postzygotic HRAS and KRAS mutations cause nevus sebaceous and Schimmelpenning syndrome. Nat Genet 44: 783787, 2012. PMID: 22683711. DOI: 10.1038/ng.2316

30 Torabinia N, Razavi SM and Shokrolahi Z: A comparative immunohistochemical evaluation of CD68 and TRAP protein expression in central and peripheral giant cell granulomas of the jaws. J Oral Pathol Med 40: 334-337, 2011. PMID: 21029180. DOI: $10.1111 /$ j.1600-0714.2010.00944.x

31 Sullivan M, Gallagher $G$ and Noonan V: The root of the problem: Occurrence of typical and atypical periapical pathoses. J Am Dent Assoc 147: 646-649, 2016. PMID: 27046538. DOI: 10.1016/j.adaj.2016.02.018

32 Gomes CC, Diniz MG, Bastos VC, Bernardes VF and Gomez RS: Making sense of giant cell lesions of the jaws (GCLJ): lessons learned from next-generation sequencing. J Pathol 250: 126-133, 2020. PMID: 31705763. DOI: 10.1002/path.5365

33 Chacon-Camacho OF, Lopez-Moreno D, Morales-Sanchez MA, Hofmann E, Pacheco-Quito M, Wieland I, Cortes-Gonzalez V, Villanueva-Mendoza C, Zenker M and Zenteno JC: Expansion of the phenotypic spectrum and description of molecular findings in a cohort of patients with oculocutaneous mosaic RASopathies. Mol Genet Genomic Med 7: e625, 2019. PMID: 30891959. DOI: $10.1002 / \mathrm{mgg} 3.625$
34 Bourdeaut F, Hérault A, Gentien D, Pierron G, Ballet S, Reynaud S, Paris R, Schleiermacher G, Baumann C, PhilippeChomette P, Gauthier-Villars M, Peuchmaur M, Radvanyi F and Delattre O: Mosaicism for oncogenic G12D KRAS mutation associated with epidermal nevus, polycystic kidneys and rhabdomyosarcoma. J Med Genet 47: 859-862, 2010. PMID: 20805368. DOI: $10.1136 /$ jmg.2009.075374

35 Farschtschi S, Mautner VF, Hollants S, Hagel C, Spaepen M, Schulte C, Legius E and Brems H: Keratinocytic epidermal nevus syndrome with Schwann cell proliferation, lipomatous tumour and mosaic KRAS mutation. BMC Med Genet 16: 6, 2015. PMID: 25928347. DOI: 10.1186/s12881-015-0146-5

36 Happle R: The categories of cutaneous mosaicism: A proposed classification. Am J Med Genet 170A: 452-459, 2016. PMID: 26494396. DOI: 10.1002/ajmg.a.37439

37 Hafner C and Groesser L: Mosaic RASopathies. Cell Cycle 12: 43-50, 2013. PMID: 23255105. DOI: 10.4161/cc.23108

38 Baumhoer D, Kovac M, Sperveslage J, Ameline B, Strobl AC, Krause A, Trautmann M, Wardelmann E, Nathrath M, Höller S, Hardes J, Gosheger G, Krieg AH, Vieth V, Tirabosco R, Amary F, Flanagan AM and Hartmann W: Activating mutations in the MAPkinase pathway define non-ossifying fibroma of bone. J Pathol 248: 116-122, 2019. PMID: 30549028. DOI: 10.1002/path.5216

39 Lee K, Seo I, Choi MH and Jeong D: Roles of mitogen-activated protein kinases in osteoclast biology. Int J Mol Sci 19: 3004, 2018. PMID: 30275408. DOI: 10.3390/ijms 19103004

40 Lac V, Nazeran TM, Tessier-Cloutier B, Aguirre-Hernandez R, Albert A, Lum A, Khattra J, Praetorius T, Mason M, Chiu D, Köbel M, Yong PJ, Gilks BC, Anglesio MS and Huntsman DG: Oncogenic mutations in histologically normal endometrium: the new normal? J Pathol 249: 173-181, 2019. PMID: 31187483. DOI: $10.1002 /$ path.5314

41 Chaubey AK, Mishra SK and Chowdhary R: Positive material identification testing of dental implant to correlate their compositions with allergic conditions. J Oral Biol Craniofac Res 9: 294-298, 2019. PMID: 31289719. DOI: 10.1016/j.jobcr.2019.05.003

42 Kim KT, Eo MY, Nguyen TTH and Kim SM: General review of titanium toxicity. Int J Implant Dent 5: 10, 2019. PMID: 30854575. DOI: 10.1186/s40729-019-0162-x

43 Friedrich RE, Eisenmann J, Röser K, Scheuer HA and Löning T: Expression of proteases in giant cell lesions of the jaws, tendon sheath and salivary glands. Anticancer Res 30: 16451652, 2010. PMID: 20592356.

Received November 22, 2020

Revised January 21, 2021

Accepted January 22, 2021 